\title{
EFEITO DO EXTRATO AQUOSO DE LEUCENA SOBRE O DESENVOLVIMENTO, ÍNDICE MITÓTICO E ATIVIDADE DA PEROXIDASE EM PLÂNTULAS DE MILHO
}

\author{
NÁDJA DE MOURA PIRES ${ }^{1}$; ISABEL REGINA PRAZERES SOUZA ${ }^{2}$ HÉLIO \\ TEIXEIRA PRATES ${ }^{2}$, TRÍCIA CRISTINA LESSA DE FARIA ${ }^{3}$, ISRAEL ALEXANDRE \\ PEREIRA FILHO ${ }^{2}$ E PAULO CÉSAR MAGALHÃES ${ }^{2}$.
}

\author{
Embrapa Milho e Sorgo. Caixa Postal 151, 35701-970, Sete Lagoas, MG.
}

\begin{abstract}
RESUMO - A leucena (Leucaena leucocephala (Lam.) de Wit), quando usada como cobertura no solo, apresenta a propriedades de controlar plantas daninhas, sendo esse efeito resultante da presença de aleloquímicos, principalmente mimosina, encontrados na parte aérea da planta. A maioria dos estudos em alelopatia refere-se apenas ao efeito do aleloquímico sobre a germinação e o crescimento da planta-teste, sem considerar os eventos celulares relacionados às mudanças fisiológicas. Com este trabalho objetivouse avaliar o efeito do extrato aquoso da leucena sobre o desenvolvimento, índice mitótico radicular e atividade da peroxidase e suas isoformas na parte aérea e raízes de plântulas de milho. Os bioensaios foram conduzidos em casa-de-vegetação utilizando-se sementes de milho híbrido desenvolvidas nas concentrações $0 ; 0,4 ; 0,8 ; 1,6 ; 3,2$ e $6,4 \%$ do extrato aquoso de leucena. Verificaram-se inibição do crescimento de raízes e redução do índice mitótico proporcional ao incremento na dose do extrato, não sendo observada divisão celular a partir da concentração de 1,6 \%. A atividade da peroxidase, tanto em raízes como em folhas, cresceu com o aumento da concentração do extrato, sem, contudo, apresentar diferença nos zimogramas de suas isoformas. A maior atividade dessa enzima, nas raízes, foi correlacionada com a presença das isoformas aniônicas, pI 4,99 e 4,86, o que possivelmente esteja contribuindo para maior espessamento das raízes, o que foi verificado nas doses elevadas do extrato. As análises por HPLC revelaram teor de mimosina crescente com aumentos na concentração do extrato, sugerindo o envolvimento desse aleloquímico no desenvolvimento das plântulas.
\end{abstract}

TERMOS ADICIONAIS PARA INDEXAÇÃO: Leucena, desenvolvimento foliar e radicular, mitose, peroxidase, isoenzimas, mimosina.

\section{EFFECT OF LEUCAENA AQUEOUS EXTRACT ON THE DEVELOPMENT, MITOTIC INDEX AND PEROXIDASE ACTIVITY IN MAIZE SEEDLINGS.}

\footnotetext{
ABSTRACT - Leucaena (Leucaena leucocephala (Lam.) de Wit) has been observed to control weeds when used as soil mulch. It contains mimosine, which, among other allelochemicals, is responsible for the allelopathic effect. The objective of the present study was to evaluate the effect of aqueous extract of leucaena on the development, root mitotic index, peroxidase activity and isoenzymes in the shoots and

Recebido: 14/11/2000 - Aceito: 22/4/2001

1. Engenheira agrônoma, bolsista recém-doutora - CNPq/Embrapa Milho e Sorgo. Caixa Postal 151, 35701-970, Sete Lagoas, MG. E-mail: nadja@cnpms.embrapa.br. Autor para correspondência.

2. Pesquisadores da Embrapa Milho e Sorgo.

3. Bolsista Iniciação Científica - CNPq/Embrapa Milho e Sorgo.
} 
roots of maize seedlings. Inhibition of root growth and reduction of the mitotic index were proportional to the aqueous extract concentration. Cell division was not observed in extract concentrations equal or above $1.6 \%$. Increase in extract concentration was followed by high peroxidase activity in roots and shoots, but no changes in peroxidase isoenzyme patterns were observed. The peroxidase activity in roots was positively correlated with the increase in anionic isoenzymes, pI 4.99 and 4.86, suggesting their participation in the thickening of roots and increased dry weight $(\mathrm{mg} / \mathrm{cm})$. High concentrations of the allelochemical mimosine were detected in concentrated aqueous extracts, possibly influencing seedling development.

ADDITIONAL INDEX TERMS: Leucaena, leaf and root development, mitosis, peroxidase, isoenzymes, mimosine.

\section{INTRODUÇÃO}

A leucena (Leucaena leucocephala (Lam.) de Wit.) é uma leguminosa originária do México, sendo encontrada em toda região tropical (Skerman, 1977). Essa planta apresenta múltiplo potencial de utilização, sendo muito empregada como fonte de proteína para alimentação animal e no reflorestamento de área degradadas, melhorando as qualidades físico-químicas $\mathrm{e}$ biológicas do solo. Além disso, Budelman (1988) observou que a cobertura do solo com leucena apresenta propriedades de controle de plantas daninhas e que esse efeito ocorre em razão da presença de aleloquímicos na parte aérea da planta.

$\mathrm{O}$ uso do extrato aquoso das folhas da leucena tem apresentado efeito alelopático sobre várias plantas, tais como alface, arroz e nas plantas daninhas desmódio (Desmodium adscendens), guanxuma (Sida rhombifolia) e assa-peixe (Vernonia polyanthes), inibindo a germinação e afetando o crescimento radicular das plantas (Kuo et al., 1982; Souza Filho et al., 1997).

A fitotoxicidade do extrato de leucena sobre várias plantas tem sido atribuída à diversidade de aleloquímicos presentes em sua composição (Chou e Kuo, 1986). Dentre esses aleloquímicos, o potencial alelopático da leucena é atribuído principalmente à mimosina, por causa da presença de um radical hidroxila na posição três e de um oxigênio na posição quatro do anel da piridina (Ward e Harris, 1976). A mimosina é um aminoácido não-protéico que ocorre nas folhas e sementes das espécies de Leucaena e Mimosa (Chou e Kuo, 1986; Jacobi e Ferreira, 1991). Várias funções dessas espécies nos agroecossistemas, principalmente da Leucaena leucocephala, têm atraído a atenção da pesquisa em virtude de seus múltiplos usos (Budelman e Vandapol, 1992).

A maioria das pesquisas em alelopatia refere-se apenas ao efeito do aleloquímico sobre a germinação e o crescimento da planta-teste, não considerando os eventos celulares relacionados às mudanças fisiológicas no sistema da planta. Prasad e Subhashini (1994) verificaram que a mimosina, em arroz, além de inibir o comprimento das raízes, reduziu a atividade da nitrato redutase, peroxidase e suas isoenzimas. Com este estudo teve-se como objetivo avaliar o extrato aquoso da leucena na fisiologia das plântulas de milho mediante $o$ desenvolvimento das plântulas, índice mitótico radicular e atividade da peroxidase e suas isoenzimas, na parte aérea e raízes.

\section{MATERIAL E MÉTODOS}

\section{Extrato aquoso de leucena}

O extrato foi obtido da parte aérea (folhas e caules jovens) de plantas leucena com três meses idade, cultivada em condições de campo. Duzentos gramas da parte aérea foram picados manualmente em pedaços de aproximadamente $2,0 \mathrm{~cm}$ e triturados em liqüidificador (3 ciclos de 15 segundos), com $300 \mathrm{~mL}$ de água à temperatura de $80{ }^{\circ} \mathrm{C}$. Em seguida, foram adicionados mais 700 $\mathrm{mL}$ de água à mesma temperatura, para evitar a degradação da mimosina (Lowry et al., 1983), obtendo-se um extrato na concentração de $20 \%$ $(\mathrm{p} / \mathrm{v})$. 


\section{Bioensaio}

Conforme metodologia descrita por Prates et al. (2000), foram utilizadas dez sementes de milho híbrido BR 3123 dispostas a $1 \mathrm{~cm}$, ao longo da margem do menor comprimento do papel germitest umedecido com o extrato ou água, cobrindo-se com duas folhas também umedecidas. Em seguida, essas folhas foram enroladas em forma de cilindro, colocando-se dois rolos por proveta de $1000 \mathrm{~mL}$. Em cada proveta foram adicionados $700 \mathrm{~mL}$ do extrato nas concentrações 0,$4 ; 0,8 ; 1,6 ; 3,2$ e $6,4 \%$ (p/v), utilizando-se água como testemunha. Os tratamentos foram dispostos em delineamento inteiramente ao acaso, com quatro repetições. Cada proveta foi envolvida em papel alumínio para evitar a entrada de luz e inibir o desenvolvimento de algas. Logo em seguida foi instalado o sistema de aeração nas provetas. As soluções foram trocadas a cada 24 horas para reduzir o efeito de fermentação e as avaliações foram realizadas oito dias após a instalação do bioensaio.

\section{Avaliação do desenvolvimento das plântulas}

Foram coletadas cinco plântulas uniformes por repetição para avaliação das seguintes características: área foliar, altura e matéria seca da parte aérea, comprimento, área e matéria seca das raízes. Para obter a matéria seca, foi utilizada estufa com ventilação forçada a $70{ }^{\circ} \mathrm{C}$ por $48 \mathrm{~h}$. Para medir a área foliar, foi empregado $\mathrm{o}$ integrador de área foliar, modelo Li-3100. O comprimento e a área das raízes foram obtidos utilizado-se o Sistema integrado para análise de raízes e cobertura do solo - SIARCS, software de processamento e análises de imagens desenvolvido pela Embrapa. Além dessas características, foi determinado o diâmetro das raízes ou espessura média utilizando-se os dados de área de projeção das raízes divididas pelo comprimento das mesmas.

\section{Índice mitótico}

Para determinação desse índice, foi empregada a metodologia descrita por Oliveira et al. (1996), com algumas modificações. Foram coletados de cada plântula dois centímetros da raiz primária, a partir da extremidade distal, e imersos em fixador de Farmer (3:1, etanol:ácido acético glacial) (Jensen, 1962), durante 2 horas, a $25{ }^{\circ} \mathrm{C}$ e, em seguida, foram transferidos para uma solução de álcool $70 \%$ e $\operatorname{armazenados}$ a $8{ }^{\circ} \mathrm{C}$. Para determinação do índice mitótico, as pontas de raízes foram tratadas na seguinte ordem: 1) água destilada por cinco minutos; 2) ácido clorídrico 1 $\mathrm{M}$ por $30 \mathrm{~min}$ à temperatura ambiente; 3) água destilada por cinco minutos e 4) orceina acética 2 $\%$ por $30 \mathrm{~min}$. As pontas das raízes coradas tiveram o ápice, $2,0 \mathrm{~mm}$ iniciais, cortado sobre lâmina de microscópio, colocando-se em seguida a lamínula e pressionando sob esta o papel de filtro para esmagamento do ápice e retirada do excesso de corante. $O$ material foi observado em microscópio ótico comum, com aumento de 1000X, contando-se o número de células em cada fase da mitose (prófase, metáfase, anáfase e telófase). Para cada tratamento foram preparadas três lâminas, avaliando-se três campos/lâmina. O índice mitótico foi obtido dividindo-se o número de células em mitose (prófase + metáfase + anáfase + telófase) pelo número total de células (intérfase + mitose) multiplicando-se por 100 .

\section{Atividade da peroxidase}

Foram coletadas cinco plântulas uniformes por repetição e armazenadas em caixas de isopor contendo gelo para transporte até o laboratório. A seleção e separação das raízes e folhas foi realizada a $4{ }^{\circ} \mathrm{C}$. A atividade da peroxidase foi determinada nas raízes e nas folhas das plântulas de milho submetidas às diferentes concentrações do extrato aquoso de leucena. As raízes e folhas foram maceradas em nitrogênio líquido e a extração protéica, realizada com tampão fosfato $50 \mathrm{mM}, \mathrm{pH} 6,0$, adicionado de $1,5 \%$ de polivinilpolipirrolidona - PVPP $(\mathrm{p} / \mathrm{v})$, fluoreto de fenilmetilsulfonila - PMSF 1,0 mM e $\mathrm{NaCl} 1 \mathrm{M}$. O volume de tampão foi calculado em relação ao matéria seca fresco das raízes e folhas, na proporção de 3 e 2 vezes, respectivamente. Em seguida, o macerado foi submetido a centrifugação a $14.000 \mathrm{rpm}$ por 30 minutos e o sobrenadante 
utilizado para análise. A atividade da peroxidase foi determinada a $30{ }^{\circ} \mathrm{C}$, utilizando-se guaiacol como substrato e absorvância lida a $470 \mathrm{~nm}$ em espectofotômetro (Souza, 1997).

\section{Focalização isoelétrica e densitometria}

Isoformas da peroxidase foram determinadas em raízes e folhas utilizando-se isogéis de agarose $1 \%(\mathrm{p} / \mathrm{v})$ contendo sorbitol 12 $\%$ (p/v) e anfólitos 6,7 \% (v/v), pH de 3 a 10, como descrito por MacAdam et al. (1992). Amostras de raízes e folhas foram dessalinizadas e concentradas utilizando-se microcon-10. Os isogéis foram submetidos à voltagem constante, $1200 \mathrm{~V}$, com pré-focalização a $1 \mathrm{~W}$ por 20 minutos e focalização a $4 \mathrm{~W}$ por $1 \frac{1}{2}$ hora. A temperatura do gel foi mantida a $10{ }^{\circ} \mathrm{C}$ durante toda a corrida. Para detecção das isoformas, os isogéis foram revelados empregando-se o método PPD-PC descrito por Imberty et al. (1984) e o ponto isoelétrico (pI) dessas for determinado por meio da utilização de marcadores, proteínas de pI previamente determinado (Amersham Pharmacia, BIOTECH, Piscataway, NJ, USA). A quantificação das isoformas da peroxidase foi realizada em densitômetro.

\section{Concentração protéica em ápice de raízes e em folha}

A concentração protéica do sobrenadante extraído de raízes e folhas foi determinado pelo do método de Bradford (1976), utilizando-se o protocolo de "microtiter plate" para leitura em placa de Elisa, e absorvância lida a $595 \mathrm{~nm}$.

Análise do extrato por HPLC - foi realizada utilizando-se a metodologia descrita por Lowry et al. (1985). Empregou-se o cromatógrafo líquido, marca Shimadzu, modelo LC-10A, adaptado com bomba LC-10AD, detetor UV/VIS e injetor de amostra automático. Foi utilizada a técnica do padrão externo, com curva de calibração linear baseada na integração da área do pico pelo método dos mínimos quadrados (curva-padrão). As condições analíticas empregadas, tanto para a curva padrão, quanto para a análise das amostras do extrato, foram: fase móvel constituída de solução aquosa de $\mathrm{NH}_{4} \mathrm{H}_{2} \mathrm{PO}_{4} 2 \%$, ajustada para pH 2,4 com $\mathrm{H}_{3} \mathrm{PO}_{4}$, coluna tipo fase reversa $\left(\mathrm{C}_{18}\right)$, Shim-pack CLC-ODS(M) com 4,6 mm x $250 \mathrm{~mm}$; fluxo de $1,0 \mathrm{~mL} \mathrm{~min}^{-1}$, volume injetado da amostra de $50 \mu \mathrm{L}$, comprimento de onda igual a $280 \mathrm{~nm}$.

\section{Análise estatística}

Os resultados foram submetidos à análise de variância (SAEG), sendo as médias comparadas pelo teste Duncan a $5 \%$ de probabilidade ou análise de regressão.

\section{RESULTADOS E DISCUSSÃO}

Na Figura 1 observa-se o fenótipo das plântulas de milho na época da colheita nota-se que houve pouca interferência do extrato de leucena sobre o desenvolvimento da parte aérea e um maior efeito sobre as raízes. Nessa fase, o menor efeito sobre a parte aérea das plântulas com oito dias após a germinação provavelmente se deve à utilização pelas plantas da reserva nutricional das sementes.

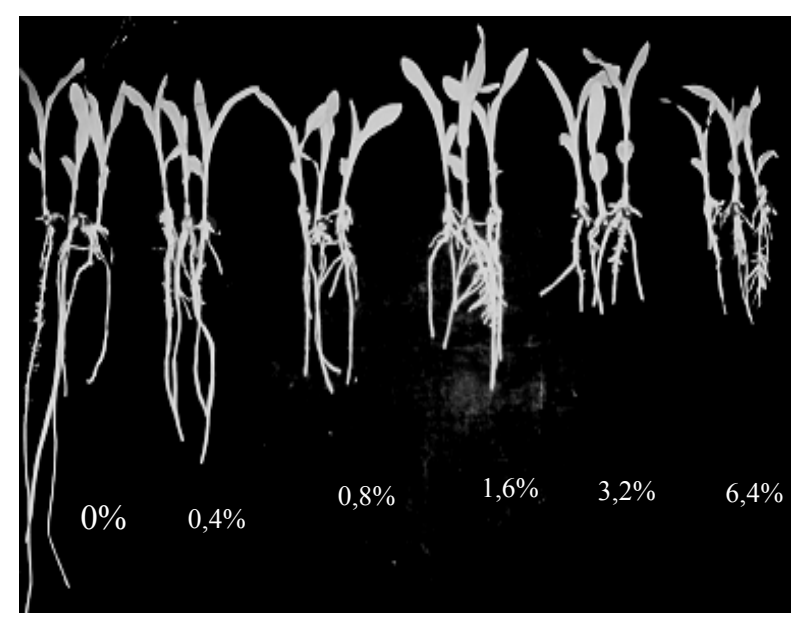

FIGURA 1 - Plântulas de milho crescidas sob diferentes concentrações (\%) do extrato aquoso da leucena. 
A avaliação das características na parte aérea mostrou que nas concentrações 0,$4 ; 0,8 ; 1,6$ e $3,2 \%$ do extrato houve um ligeiro estímulo ao desenvolvimento das plântulas, e apenas na dose de $6,4 \%$ do extrato houve uma redução do crescimento (Figura 2).
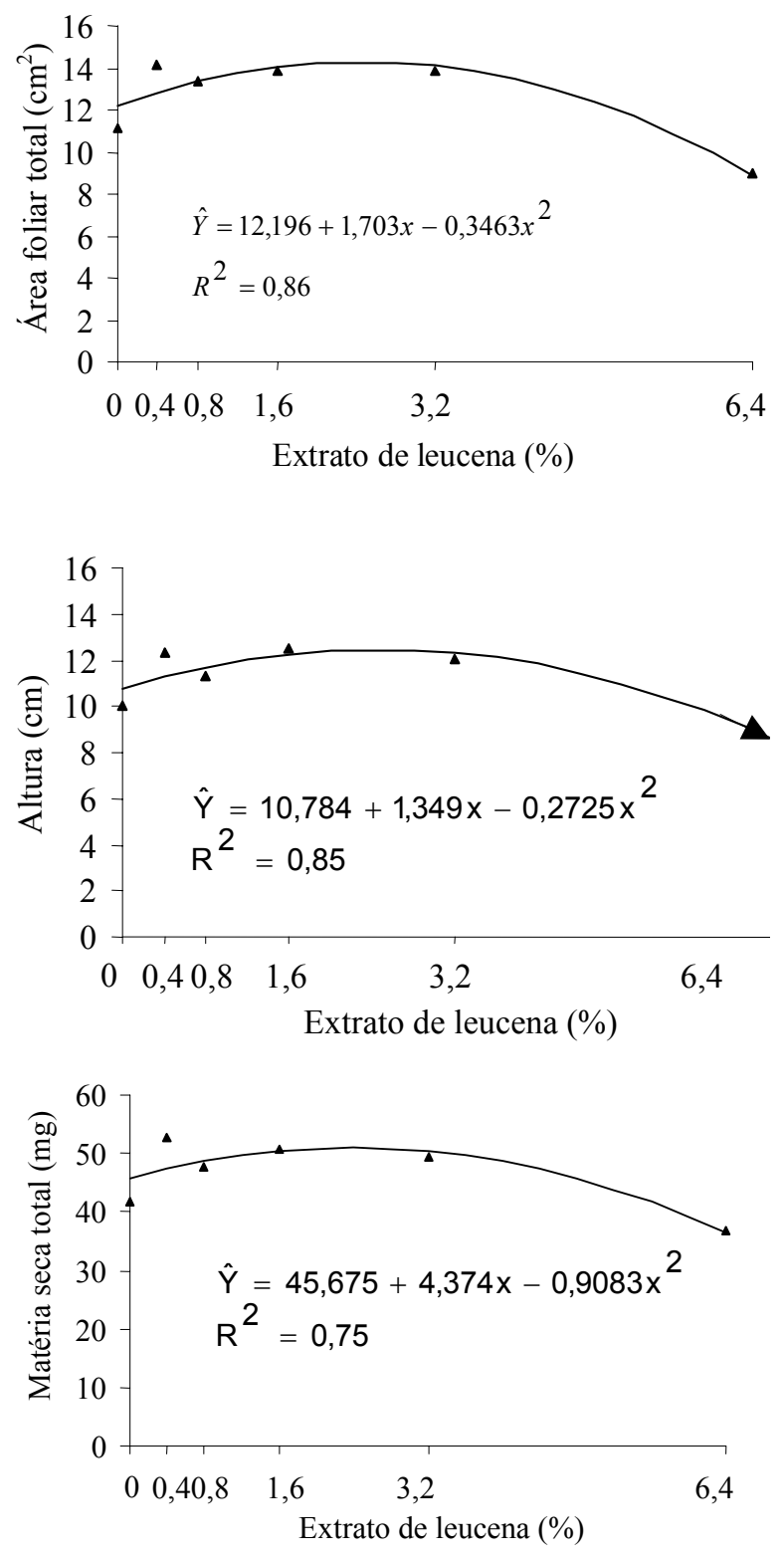

FIGURA 2 - Características avaliadas na parte aérea das plântulas de milho submetidas a diferentes concentrações do extrato aquoso da leucena
Nas raízes, observa-se que houve redução em todas as características avaliadas, e o efeito foi crescente com o aumento da dose (Figura 3), resultados semelhantes foram observados por Prates et al. (2000). De acordo com Souza Filho et al. (1997), a interferência no desenvolvimento da radícula é um dos melhores indicadores para o estudo de extratos com potencial alelopático.

Entretanto, quando se consideram as relações matéria seca/comprimento de raiz $\left(\mathrm{mg} . \mathrm{cm}^{-1}\right)$ e área/comprimento das raízes $\left(\mathrm{mm}^{2} \cdot \mathrm{mm}^{-1}\right)$, verificase que houve um espessamento da raiz (Tabela 1) observado na maior concentração do extrato.

Os resultados das observações citológicas em células meristemáticas das raízes de plântulas de milho, tratadas com diferentes concentrações do extrato de leucena, são apresentadas na Figura 4 e Tabela 2.

TABELA 1 - Relações matéria seca/comprimento e área/comprimento das raízes de plântulas de milho submetidas a diferentes concentrações do extrato aquoso de leucena

\begin{tabular}{ccc}
\hline Tratamentos & $\begin{array}{c}\text { Matéria } \\
\text { seca/comprimento } \\
\left(\mathrm{mg} \cdot \mathrm{cm}^{-1}\right)\end{array}$ & $\begin{array}{r}\text { Área/comprimento } \\
\left(\mathrm{mm}^{2} \cdot \mathrm{mm}^{-1}\right)\end{array}$ \\
\hline $0,215 \mathrm{~b}$ & $0,658 \mathrm{~b}$ \\
$0,4 \%$ & $0,178 \mathrm{~b}$ & $0,618 \mathrm{c}$ \\
$0,8 \%$ & $0,210 \mathrm{~b}$ & $0,710 \mathrm{a}$ \\
$1,6 \%$ & $0,218 \mathrm{~b}$ & $0,713 \mathrm{a}$ \\
$3,2 \%$ & $0,232 \mathrm{~b}$ & $0,725 \mathrm{a}$ \\
$6,4 \%$ & $0,313 \mathrm{a}$ & $0,750 \mathrm{a}$ \\
\hline $\mathrm{CV}(\%)$ & 16,411 & 4,646 \\
\hline
\end{tabular}

Médias com a mesma letra não diferem pelo teste Duncan a $5 \%$ de probabilidade. 

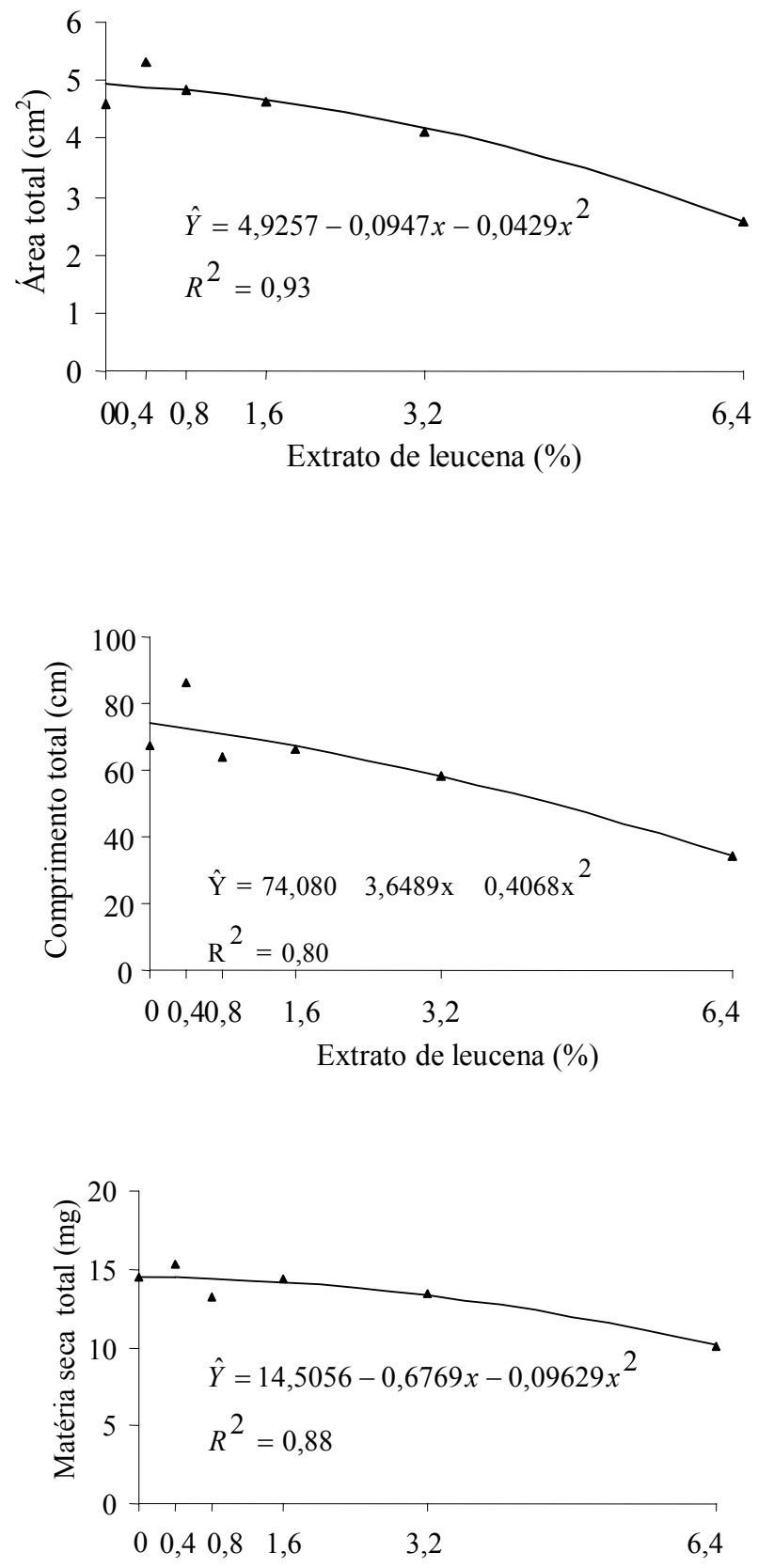

Extrato de leucena (\%)

FIGURA 3 - Características avaliadas nas raízes das plântulas de milho submetidas a diferentes concentrações do extrato aquoso da leucena.

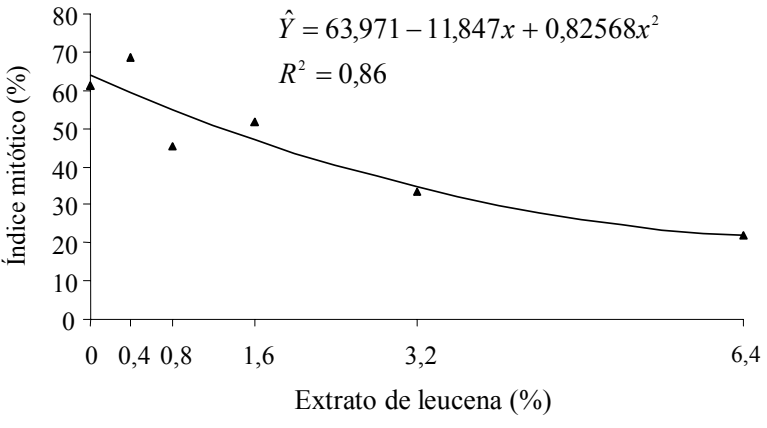

FIGURA 4 - Índice mitótico em células meristemáticas de raízes de plântulas de milho expostas a diferentes concentrações do extrato de leucena.

Com o aumento da concentração do extrato de leucena, o valor do índice mitótico foi continuamente reduzido (Figura 4), sendo o maior efeito depressivo verificado na concentração de 6,4 $\%$, em que o índice mitótico não atingiu mais do que $22 \%$ comparado a $64 \%$ do tratamentocontrole. Uma redução de $50 \%$ no índice mitótico foi observada na concentração de 3,6 \% do extrato. Comparando-se as freqüências das diferentes fases da mitose dentro de cada tratamento (Tabela 2), notaram-se maior freqüência de prófase e menor freqüência das outras fases subseqüentes. Com o aumento da concentração do extrato, houve uma drástica redução no índice mitótico, com paralisação do crescimento radicular a partir da dose de $1,6 \%$, em conseqüência principalmente da ausência de telófase.

Essa interferência na divisão celular causada pela ação do extrato com acentuado efeito sobre a morfologia do sistema radicular (Figura 3) provavelmente representa um dos mecanismos de ação do extrato sobre o desenvolvimento da plantateste.

A atividade da peroxidase nas raízes foi mais influenciada diretamente pelas concentrações do extrato de leucena do que na parte aérea, como pode ser verificado pelo maior aumento da atividade enzimática nas doses mais elevadas do extrato (Figura 5A). 
Efeito do extrato aquoso de leucena $\ldots$

TABELA 2 - Freqüência das diferentes fases da mitose em células meristemáticas de raízes de plântulas de milho desenvolvidas sob diferentes concentrações do extrato de leucena.

\begin{tabular}{|c|c|c|c|c|c|}
\hline \multirow{2}{*}{$\begin{array}{l}\text { Concentração do } \\
\text { extrato de } \\
\text { leucena }(\%)\end{array}$} & \multirow{2}{*}{$\begin{array}{l}\text { Número de } \\
\text { células em } \\
\text { mitose }\end{array}$} & \multicolumn{4}{|c|}{$\%$ de células nas fases } \\
\hline & & Prófase & Metáfase & Anáfase & Telófase \\
\hline 0 & $127 \mathrm{a}$ & $55,96 \mathrm{ab}$ & $1,80 \mathrm{ab}$ & $1,38 \mathrm{a}$ & $2,02 \mathrm{a}$ \\
\hline 0,4 & $106 \mathrm{ab}$ & $62,46 \mathrm{a}$ & $2,41 \mathrm{a}$ & $1,47 \mathrm{a}$ & $2,17 \mathrm{a}$ \\
\hline 0,8 & $62 \mathrm{bc}$ & $43,06 \mathrm{bc}$ & $0,75 \mathrm{ab}$ & $0,87 \mathrm{a}$ & $0,66 \mathrm{ab}$ \\
\hline 1,6 & $54 \mathrm{c}$ & $50,51 \mathrm{ab}$ & $0,85 \mathrm{ab}$ & $0,19 \mathrm{a}$ & $0,00 \mathrm{~b}$ \\
\hline 3,2 & $50 \mathrm{c}$ & $32,26 \mathrm{~cd}$ & $0,42 \mathrm{~b}$ & $0,61 \mathrm{a}$ & $0,00 \mathrm{~b}$ \\
\hline 6,4 & $24 \mathrm{c}$ & $21,67 \quad d$ & $0,00 \mathrm{~b}$ & $0,45 \mathrm{a}$ & $0,00 \mathrm{~b}$ \\
\hline
\end{tabular}

Médias seguidas de mesma letra não diferem entre si pelo teste Duncan a $5 \%$ de probabilidade.

Entretanto, a concentração protéica, tanto na parte aérea quanto nas raízes das plântulas, aumentou proporcionalmente em relação à concentração do extrato de leucena (Figura 5B). Embora tenha havido influência do extrato sobre a atividade da peroxidase, não houve repressão ou indução da expressão de isoenzimas, como pode ser verificado nos zimogramas, tanto na parte aérea como em raízes de milho (Figura 6). Entretanto, em folhas e raízes de arroz, Prasad e Subhashini (1994) verificaram que a mimosina reprimiu a expressão de isoformas da peroxidase.

Houve relação negativa entre atividade da peroxidase na parte aérea e as características área foliar (coeficiente de correlação de Pearson = $-0,85)$, altura $(\mathrm{r}=-0,92)$ e matéria seca da parte aérea $(\mathrm{r}=-0,87)$ e entre a atividade da peroxidase na raiz com a área $(\mathrm{r}=-0,98)$, comprimento $(\mathrm{r}=$ $0,99)$ e matéria seca radicular $(\mathrm{r}=-0,98)$, sugerindo uma possível relação de causa e efeito (Figuras 2 e 3). Entretanto, em relação às raízes, o aumento na atividade da enzima foi também paralelamente seguido por um acréscimo nas relações matéria seca/comprimento de raiz e área/comprimento de raiz (Tabela 1), resultante de um espessamento radicular (mg de matéria seca/cm de raiz) (Figura 3)

Nas raízes, as isoformas aniônicas pI 4,99 e 4,86 (Tabela 3) apresentaram níveis de atividades crescentes em concentrações mais elevadas do extrato, provavelmente contribuindo para o aumento verificado na atividade da peroxidase. Diversos trabalhos têm sugerido que as isoformas aniônicas apresentam maior contribuição para a lignificação dos tecidos (Lewis e Yamamoto, 1990; Gaspar et al., 1991), o que nesse caso poderia estar associada ao maior espessamento e endurecimento das raízes, verificado nas concentrações mais elevadas do extrato. 

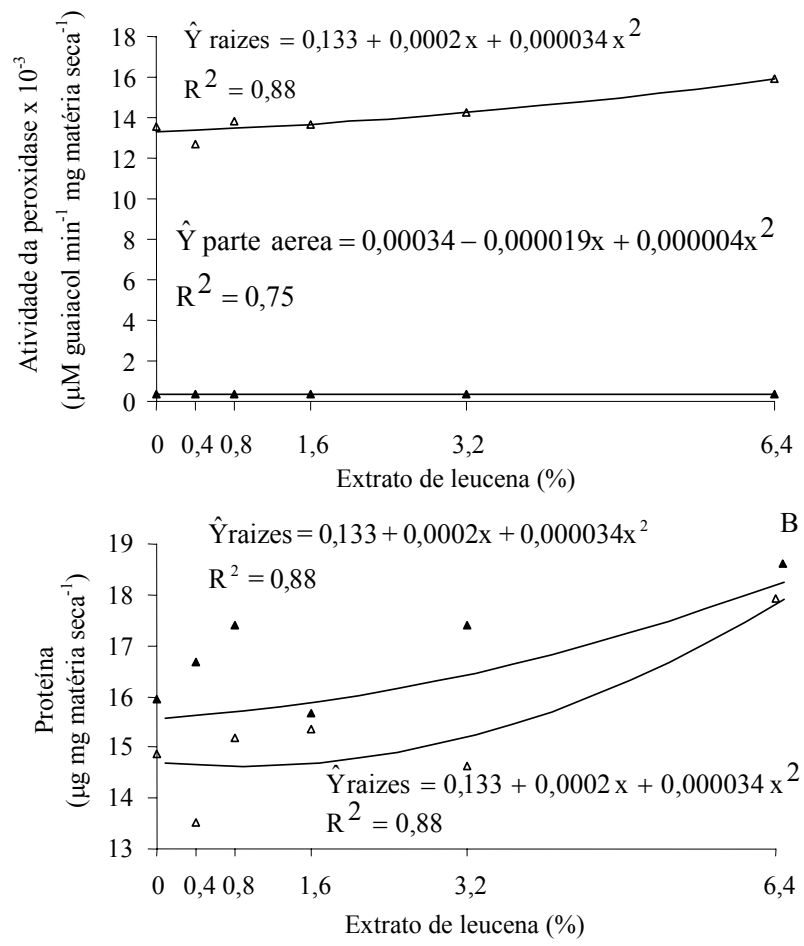

FIGURA 5 - Atividade da peroxidase (A) e concentração protéica $(B)$ na parte aérea $(\boldsymbol{A})$ e raízes $(\Delta)$ de plântulas de milho submetidas a diferentes doses do extrato de leucena.

Parte Aérea

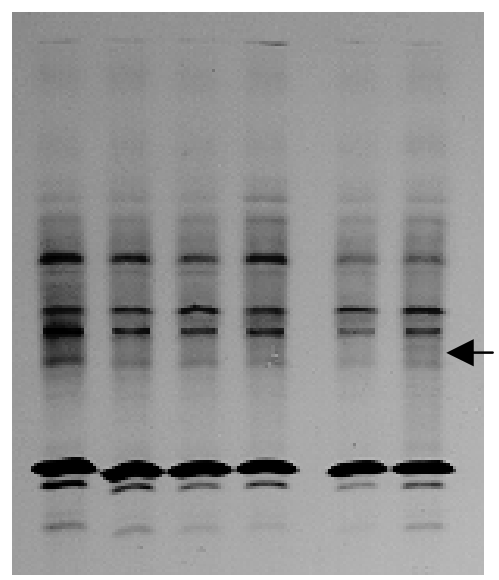

$\quad$ pI
7.84
6.85
6,28
Aplicação das
amostras
4,81
4,65
4,31

$\begin{array}{llllll}0 & 0,4 & 0,8 & 1,6 & 3,2 & 6,4\end{array}$
$\mathrm{Na}$ Figura 7 são observados os cromatogramas de HPLC dos extratos de leucena em diferentes concentrações. A identificação no extrato da mimosina, nas concentrações $0,4 \%$ até $6,4 \%$, corresponderam a uma quantidade de 23,65 a 186,54 $\mu \mathrm{g} \mathrm{mL} \mathrm{m}^{-1}$ desse aleloquímico. A curva de calibração apresentou alto coeficiente de determinação $\left(r^{2}>0,99\right)$, mostrando boa correlação entre a concentração do extrato e o teor de mimosina. $\mathrm{O}$ efeito fitotóxico observado no bioensaio pode estar relacionado ao aleloquímico mimosina, presente em altas concentrações no extrato.

Uma gama de evidências do envolvimento da peroxidase no controle do crescimento celular vem sendo largamente estudada e entre essas têm-se o catabolismo do ácido indolacético (IAA) (Sánchez-Bravo et al., 1990), e a perda da plasticidade da parede celular através do "cross-linking" de fenólicos a polissacarídeos da parede celular (Biggs e Fry, 1987), e esse último processo resulta no enrigecimento irreversível, o qual age contrabalançando a força de expansão de turgescência. $O$ aumento na atividade da peroxidase, correlacionado ao aumento na atividade das isoformas aniônicas, sugerem a

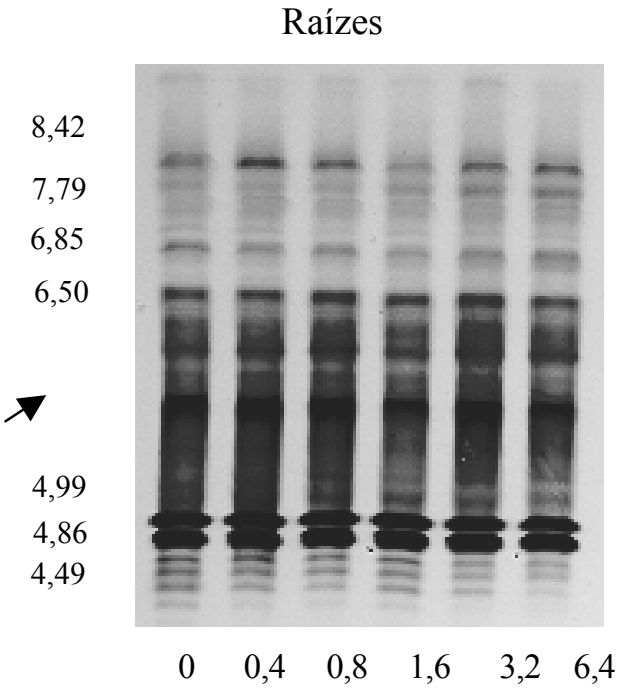

Concentração do extrato de leucena (\%)

FIGURA 6 - Zimograma de isoformas da peroxidase de parte aérea e de raízes de plântulas de milho submetidas a diferentes concentrações do extrato aquoso de leucena. 
Efeito do extrato aquoso de leucena $\ldots$

63

TABELA 3 - Densitometria das isoformas da peroxidase presentes na parte aérea e raízes de plântulas de milho submetidas a diferentes concentrações do extrato de leucena.

\begin{tabular}{ccccccc}
\hline $\begin{array}{c}\text { Concentração } \\
\text { do extrato de } \\
\text { leucena (\%) }\end{array}$ & \multicolumn{5}{c}{ Isoformas $\left(^{*}\right)$ pI } \\
\cline { 2 - 7 } & 6,85 & 4,81 & 4,65 & 6,85 & 4,99 & 4,86 \\
\hline 0 & $1,60 \mathrm{~b}$ & $45,13 \mathrm{a}$ & $10,27 \mathrm{a}$ & $6,37 \mathrm{a}$ & $2,73 \mathrm{c}$ & $4,93 \mathrm{~b}$ \\
0,4 & $1,79 \mathrm{ab}$ & $42,85 \mathrm{ab}$ & $5,27 \mathrm{a}$ & $6,03 \mathrm{a}$ & $2,73 \mathrm{c}$ & $5,53 \mathrm{ab}$ \\
0,8 & $2,62 \mathrm{a}$ & $46,72 \mathrm{a}$ & $6,66 \mathrm{a}$ & $6,66 \mathrm{a}$ & $3,66 \mathrm{bc}$ & $6,74 \mathrm{ab}$ \\
1,6 & $1,77 \mathrm{ab}$ & $44,67 \mathrm{a}$ & $7,90 \mathrm{a}$ & $7,76 \mathrm{a}$ & $4,51 \mathrm{ab}$ & $7,32 \mathrm{ab}$ \\
3,2 & $1,89 \mathrm{ab}$ & $41,20 \mathrm{ab}$ & $6,51 \mathrm{a}$ & $7,57 \mathrm{a}$ & $5,55 \mathrm{a}$ & $7,90 \mathrm{ab}$ \\
6,4 & $2,13 \mathrm{ab}$ & $34,24 \mathrm{~b}$ & $7,12 \mathrm{a}$ & $7,46 \mathrm{a}$ & $5,48 \mathrm{a}$ & $9,16 \mathrm{a}$ \\
\hline
\end{tabular}

Médias com a mesma letra na coluna não diferem significativamente pelo teste de Duncan a $5 \%$ de probabilidade.

* Isoformas mensuradas no densitômetro

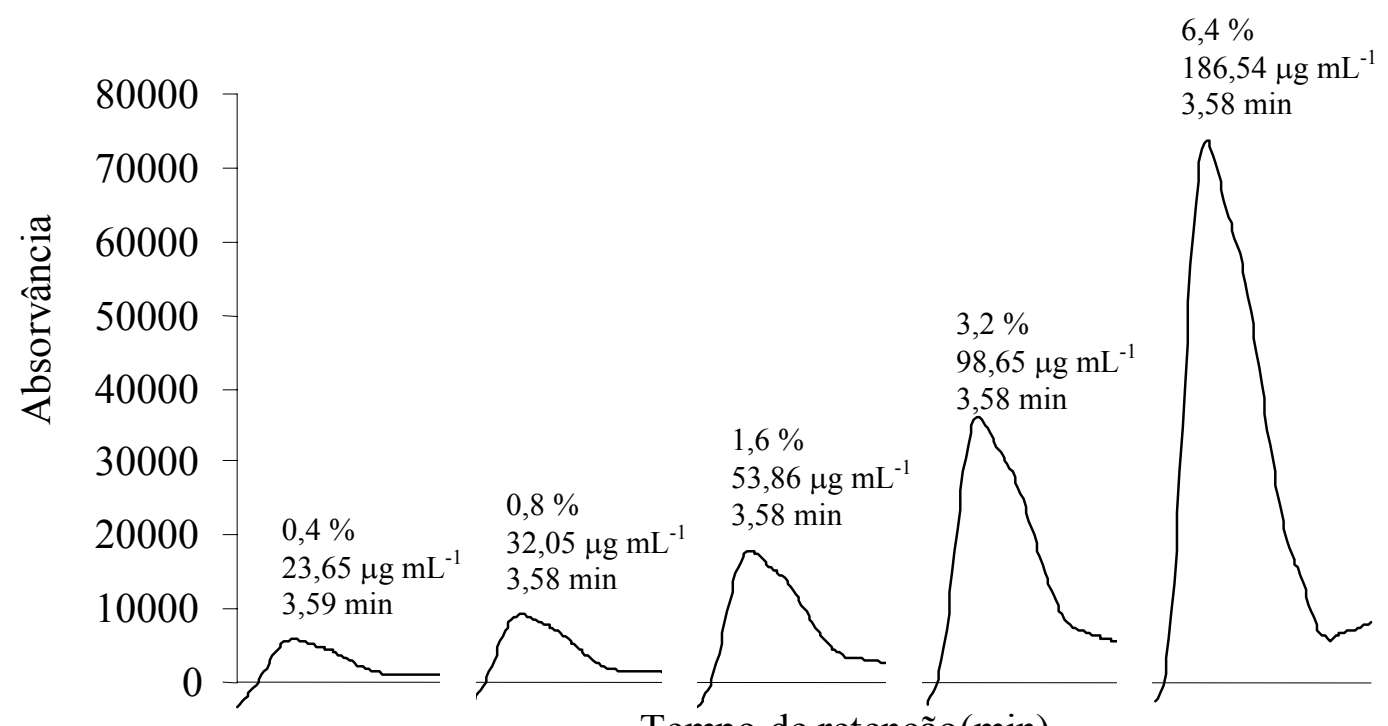

Tempo de retenção(min)

FIGURA 7 - Cromatogramas de HPLC mostrando o teor de mimosina em diferentes concentrações do extrato de leucena. 
participação desta enzima na redução do crescimento radicular verificado nas doses crescentes do extrato de leucena.

Pelos resultados deste estudo verificouse que nas concentrações maiores do que 1,6\% houve inibição no desenvolvimento das raízes de milho, sugerindo provalvemente que a inibição da divisão celular e o aumento na atividade de isoformas da peroxidase sejam mecanismos de ação do extrato da parte aérea da leucena sobre as plantas.

\section{AGRADECIMENTO}

Agradecemos ao laboratorista Nilson Machado Lopes, do Laboratório de Agroquímica da Embrapa Milho e Sorgo, pelo auxílio nas análises cromatográficas por HPLC.

\section{REFERÊNCIAS}

BIGGS, K.J.; \& FRY, S.C. Phenolic cross-linking in the cell wall. In: Cosgrove D.J.; Knievel D.P. (Eds). Physiology of Cell Expansion During Plant Growth. Rockville, American Society of Plant Physiologists, 1987. p. 46-57.

BRADFORD, M.M. A rapid and sensitive method for the quantitation of microgram quantities of protein utilizing the principle of protein-dye binding. Analytical Biochemistry, 72: 248254, 1976.

BUDELMAN, A. The performance of the leaf mulches of Leucaena leucocephala, Flemingia macrophylla and Gliricidia sepium in weed control.Agroforestry Systems, 6:137-145, 1988.

BUDELMAN, A.; VANDAPOL, F. Farming system research and the quest for a sustainable agriculture. Agroforestry Systems, 19: 187206, 1992.

CHOU, C.H.; KUO Y.L. Allelopathic research of subtropical vegetation in taiwan. III. Alelopathic exclusion of understrory by Leucaena leucocephala (Lam.) de Wit. Journal of Chemical Ecology, 12: 1431-1448, 1986.
GASPAR, T.H.; PENEL. C.; HAGEGE, D.; GREPPIN, H. Peroxidases in plant growth, differentiation, and development processes. In: Lobarzewski, J.; Greppin, H.; Penel, C.; Gaspar, T.H. (Eds.). Biochemical, Molecular, and Physiological Aspects of Plant Peroxidases. Lublin, Poland: University $M$. Curie-Sklodowska/University Geneva, 1991. p. 249-280.

IMBERTY, A.; GOLDBERG, R.; \&CATESSON, A-M. Tetramethylbenzidine and $p$ phenylenediamine-pyrocatechol for peroxidase histochemistry and biochemistry: two new, non-carcinogenic chromogens for investigating lignification process. Plant Science Letters, 35: 103-108, 1984.

JACOBI, U.S.; \& FERREIRA, A.G. Efeitos alelopáticos de Mimosa bimucronata (DC) OK sobre espécies cultivadas. Pesquisa Agropecuária Brasileira,.26: 935-943, 1991.

JENSEN, W.A. Botanical histochemistry. New York, Freeman, W. H., 1962.

KUO, Y. L.; CHOU, C. H.; \& HU, T. W. Allelopathic potencial of Leucaena leucocephala. Leucaena Research Report, 3: 65-70, 1982.

LEWIS, N.G.; \& YAMAMOTO, E. Lignin: occurrence, biogenesis and biodegradation. Annual Review of Plant Physiology and Plant Molecular Biology, 41: 455-495, 1990.

LOWRY, J.B.; TANGENDADJAJA B.; COOK, N.W. Measurement of mimosine and its metabolites in biological materials. Journal Science Food Agriculture, 36: 799-807, 1985.

LOWRY, J.B.; TANGENDADJAJA, M.; \& TANGENDADJAJA B. Autolysis of mimosine to 3-hydroxy-4-1(H)pyridone in green tissues of Leucaena leucocephala. Journal Science Agriculture, 34: 529-533, 1983. 
MacADAM, J.W.; SHARP, R.E.;\& NELSON, C.J. Peroxidase activity in the leaf elongation zone of tall fescue. II. Spatial distribution of apoplastic peroxidase activity in genotypes differing in length of the elongation zone. Plant Physiology, 99: 879-885, 1992.

OLIVEIRA, V.R.; SCAPIM, C.A.; OLIVEIRA JR., R.S.; \& PIRES, N.M. Efeito do herbicida trifluralin sobre a germinação de sementes e índice mitótico em raízes de milho (Zea mays L.). Revista Unimar, 18: 537-544, 1996.

PRASAD, M.N.V.; \& SUBHASHINI, P. Mimosineinhibited seed germination, seedling growth, and enzymes of Oryza sativa L. Journal of Chemical Ecology, 20: 1689-1696, 1994.

PRATES, H.T.; PAES, J.M.V.; PIRES, N.M.; PEREIRA FILHO, I.A.; \& MAGALHÃES, P.C. Efeito do extrato aquoso de leucena na germinação e no desenvolvimento do milho. Pesquisa Agropecuária Brasileira, 35: 909914, 2000.
SÁNCHEZ-BRAVO J., ORTUÑO A, ACOSTA M, SABATER F, \& OLSSON O. Presence of indole-3-acetic acid decarboxylating activity in hypocotyl sections of etiolated Lupinus albus seedlings. Journal Plant Physiology, 134: 517-523, 1990.

SOUZA FILHO, A.P., RODRIGUES, L.R.A., \& RODRIGUES, T.J.D. Efeitos do potencial alelopático de três leguminosas forrageiras sobre três invasoras de pastagens. Pesquisa Agropecuária Brasileira, 32: 165-170, 1997.

SOUZA, I.R.P. Gibberellic acid and dwarfism effects on peroxidase activity and secretion of anionic isoenzymes into the cell wall of expanding maize (Zea mays L.) leaf blade. Logan, Utah State University, 1997. 104p. Ph.D. Dissertation

WARD, K.A.; \& HARRIS, R.L.N. Inibition of wool follicle DNA synthesis by mimosine and related 4(1H)-pyridones. Australian Journal Biology Science, 29: 189-196, 1976. 